\title{
ANÁLISES URBANAS DE INDIANA - SP: UMA VISÃO SEGUNDO AS CONCEPÇÕES
} DE JANE JACOBS

\author{
Luciana Bernardes, Luiz Arthur Amorim, Melissa Bassoli Neves, Natália De Souza, Mayara Pissutti \\ Albano \\ Universidade do Oeste Paulista - UNOESTE. Curso de Arquitetura e Urbanismo, Presidente Prudente - SP. E-mail: \\ ma.albano@unoeste.br
}

\section{RESUMO}

Indiana, objeto de estudo do presente artigo, é uma cidade de pequeno porte do estado de São Paulo. Sua fundação data do início do século XX, e se deu à partir de um posto de recursos no caminho entre o estado de São Paulo e Mato Grosso. Hoje sua população é de aproximadamente cinco mil habitantes. Através de levantamentos de campo, foi desenvolvida uma discussão sobre alguns aspectos da utilização dos espaços públicos urbanos buscando transmitir o olhar particular da autora Jane Jacbos, importante teórica, autoras de diversos livros sobre percepção do espaço urbano, para a realidade local. Conhecer as caraterísticas de uma determinada cidade é base fundamental para o desenvolvimento do planejamento urbano, que deve ser munido de instrumentos de gestão condizentes com os hábitos e culturas do local a se intervir; justifica-se desta forma a importância de tais levantamentos de análises.

Palavras - chave: Indiana -SP, Espaço Público, Planejamento Urbano, Análises Sócioespaciais, Vitalidade Urbana.

\section{URBAN ANALYSIS CITY OF INDIANA - SP: A VISION ACCORDING TO KNOWLEDGE OF JANE JACOBS}

\begin{abstract}
Indiana, studied object of this article, is a small town in the state of São Paulo. Its foundation dates from the early twentieth century, and it was given from a resource station in the path between the state of São Paulo and Mato Grosso. Today its population is approximately five thousand inhabitants. Through field surveys, a discussion of some aspects of the use of urban public spaces seeking to convey the particular look of author Jane Jacbos, important theoretic, author of several books on perception of urban space, to the local reality. Knowing some characteristics of a particular city is fundamental to the development of urban planning, which should be provided with management tools consistent with the habits and cultures of the local base to intervene; for this reason the importance of such analysis.
\end{abstract}

Keywords: Indiana, Public Space, Urban Planning, Socio-spatial analysis, Urban Vitality. 


\section{INTRODUÇÃO E OBJETIVOS}

O presente artigo tem como objetivo a análise urbana da cidade de Indiana - SP segundo Jacobs (2007), que discute questões relativas ao uso do espaço urbano, sua configuração e os conflitos socioespaciais comuns em diversas cidades, buscando trazer tais discussões para a realidade da referida cidade, localizada no interior do estado de São Paulo.

A análise e a discussão do espaço intra-urbano (VILLAÇA, 1998) nas cidades brasileiras são referenciais para compreensão dos processos que nelas ocorrem. Conhecer a realidade urbana gera subsídios ao planejamento, visto que é um meio de juntar informações que venham contribuir para a qualidade de vida da população, passando a existir a necessidade de diagnóstico da existência ou não de condições habitação e vivência, em termos sociais, ambientais, econômicos, entre outros (ALBANO, 2013).

Quando se compreende a dimensão da ação humana como protagonista da dinâmica e da transformação do espaço urbano, conclui-se que deve ser um compromisso a realização de ações que visem a melhorar, organizar, planejar e executar suas atividades dentro deste espaço, sempre respeitando o meio ambiente e a sociedade inserida nesse espaço. Assim têm-se a dimensão da importância de levantamentos e análises urbanas como as apresentadas a seguir.

\section{METODOLOGIA}

A metodologia seguida foi baseada em levantamentos bibliográficos, buscando compreender os conceitos relativos ao tema abordado e a formulação de uma avaliação lógica da problemática. Em seguida foram realizados levantamento de campo através da observação intensiva.

\section{ANÁLISES URBANAS DA CIDADE DE INDIANA - SP}

Indiana, é uma cidade de porte pequeno, localizada no interior do estado de São Paulo, próxima à Presidente Prudente (figura 1), sede administrativa do Pontal do Paranapanema. Dista cerca de $600 \mathrm{~km}$ da capital do estado, e possui aproximadamente cinco mil habitantes. O nome da cidade "Indiana" foi dado em decorrência dos inúmeros grupos indígenas que habitavam o espaço onde a cidade foi edificada (web site oficial do município - http://www.indiana.sp.gov.br). 


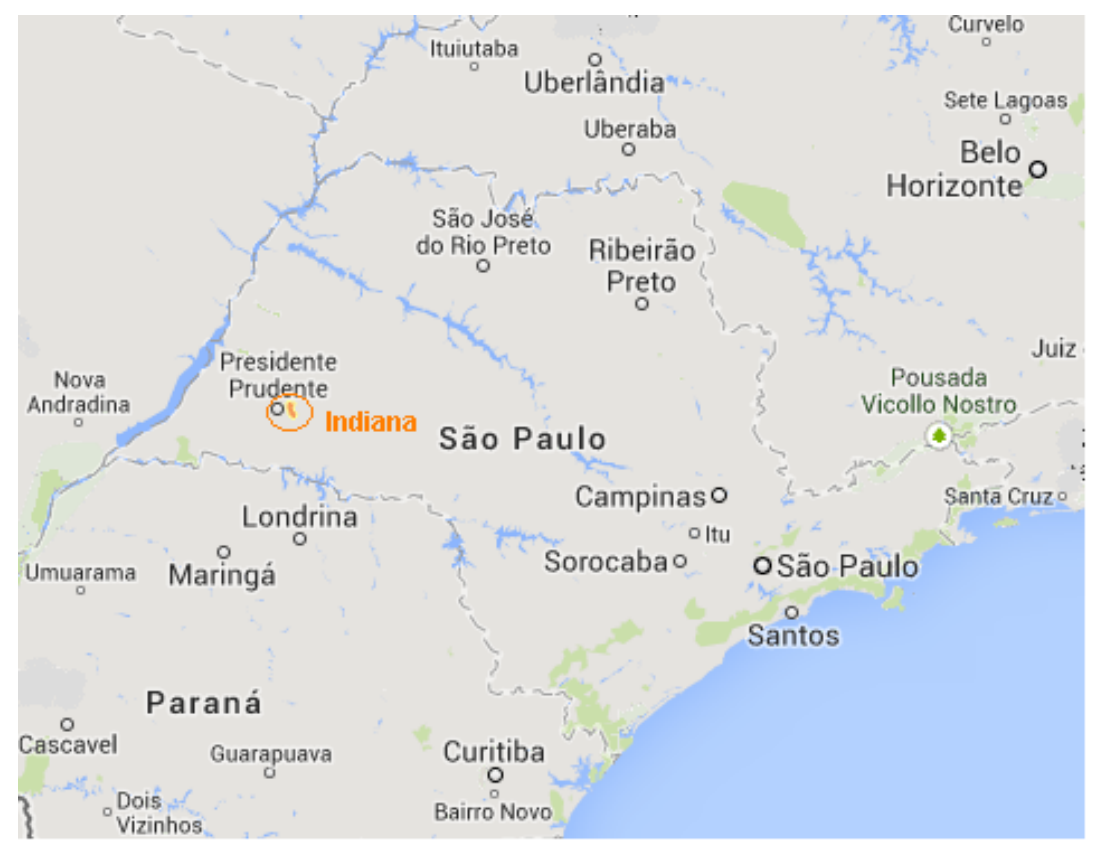

Figura 1. Localização de Indiana no estado de São Paulo Fonte: http://cidades.ibge.gov.br/(Acesso em: 12 de maio de 2014).

A fundação da cidade assenta-se na abertura da Estrada Boiadeira, que nos primeiros anos do século XX começou a rasgar o Sertão do Vale do Paranapanema, desde o povoado de São Matheus, em Campos Novos Paulista, até a margem do rio Paraná, na divisa com o sul de Mato Grosso. Do lado do Mato Grosso, a parte fronteira, se achava em difíceis condições de acesso, os habitantes do sul de ambos os Estados, só podiam alcançar a Capital de São Paulo e o Rio de Janeiro, indo pelo rio Paraguai ou por Uberaba- MG. Havia, portanto, grande necessidade de abrirse comunicação entre estes dois Estados, segundo o website oficial da cidade.

Foi estabelecido nos campos de "Laranja Doce" um posto de recursos. Para dirigi-lo foi chamado Alonso Junqueira, que construiu o primeiro rancho coberto com zinco, no local onde hoje se encontra o centro de Indiana. A construção dessa estrada trouxe o deslocamento de mão de obra, a valorização do local e principalmente possibilitou o acesso ao mesmo. Desta forma a cidade foi se desenvolvendo ao redor deste rancho, seguindo a tendência descrita por Villaça (2001), onde as vias regionais de transporte constituem o mais poderoso elemento na atração da expansão urbana.

As cidades, de uma maneira geral, antes das construções das ferrovias, cresciam ao longo dos principais caminhos. Desta forma se deu o desenvolvimento da cidade de Indiana, inicialmente ao longo da Estrada dos Boiadeiros, hoje Rua Visconde do Rio Branco. Porém, outro ponto fundamental para a concepção da cidade foi a construção da estação ferroviária, que de 
início foi aberta como posto telegráfico em 1917. Ainda como fator de direção de expansão urbana, o transporte e suas vias muito contribuíram para a estruturação da cidade.

Segundo o website oficial da cidade, a ferrovia que passa por Indiana teve papel fundamental para seu desenvolvimento. Evidentemente o centro ficou em um dos dois lados da estrada de trem, sendo este o setor mais valorizado da cidade. A referida cidade, assim como inúmeras cidades do sul do Brasil atravessadas por ferrovias, expandiu-se propositalmente a partir da praça central, local este com mais atrativos, e, portanto mais valorizado. A igreja, localizada também no centro, foi um importante ponto de referência para os moradores da cidade que por ali se instalaram, como também para o desenvolvimento do comércio e setor de serviços.

Outro ponto fundamental que favoreceu o desenvolvimento local foi a instalação da Companhia Cima, indústria produtora telhas de barro e tijolos, que escolheu Indiana em função da grande quantidade de matéria prima encontrada na região. Muitas das pequenas fábricas que existem hoje no município são procedentes desta indústria, visto que muitas pessoas que lá trabalharam, além de se instalarem por ali aprenderam as técnicas empregadas na indústria e mesmo quando a fábrica transferiu-se para Presidente Prudente, ali se mantiveram e foram passando as técnicas de pai para filho. Por esse motivo que vemos atualmente tantas olarias na cidade.

\section{O USO DOS ESPAÇOS PÚBLICOS EM INDIANA - SP}

O espaço público é um conceito próprio do urbanismo, é um espaço utilizado como lugar de representação e de expressão coletiva da sociedade (BORJA, 2003); espaços que geram, amparam, e tornam mais fácil as relações sociais, bem como as culturais em uma cidade (CARMONA, et al,2003 appud BALLULA, 2010).

\section{O uso das calçadas}

Segundo Jacobs (2007), as calçadas e os espaços públicos são lugares onde ocorrem as trocas de confiança e a vida social através do contato. Para que isso ocorra, é necessário que "as pessoas se sintam seguras e protegidas na rua em meio a tantos desconhecidos" (JACOBS, 2007, p. 30). Na cidade de Indiana/SP as calçadas são o espaço onde a vida social acontece através do contato interpessoal. A soma destes contatos que se dão casualmente nas ruas e calçadas atribui uma identidade às pessoas, que passam a se conhecer e, criam uma rede de respeito e confiança mútua e também um apoio para possíveis dificuldades pessoal ou da vizinhança. A rua deixa de ser 
impessoal em resultado da convivência entre as pessoas e com o passar do tempo, é possível estender esta convivência pública com os familiares no dia-a-dia.

Os maiores agentes de sociabilização informal da cidade são os donos de bares, lojas, farmácias e prestadores de serviços. Estes se tornam figuras públicas que espalham notícias e sabem as notícias e sem estas pessoas o contato nas ruas não existiriam. Este contato e troca de confiança, juntamente com o sentimento de pertencimento e apropriação do espaço público, promovido pelo contato nas ruas e calçadas, são os fatores que promovem a segurança da rua. Onde todos desempenham um importante papel de zeladores da cidade.

O sentimento de apropriação deste espaço público é percebido quando os moradores no final da tarde varrem suas calçadas e lavam para sentarem durante a noite. É neste período que os moradores fazem caminhada e colocam a conversa em dia parando para conversar com os vizinhos que estão sentados nas calçadas. Quando param por mais tempo logo chamam para entrar na casa, ou seja, se apropriam do espaço público. A observação dessa dinâmica nas calçadas ratifica a afirmação de Jacobs $(2007$, p.35) de que "uma rua movimentada consegue garantir a segurança; uma rua deserta, não."

\section{O uso dos espaços de lazer dos bairros}

Os espaços públicos abertos de lazer proporcionam diversos benefícios para a melhoria da habitabilidade do ambiente urbano, dos quais podem ser destacados o desenvolvimento de práticas sociais, momentos de lazer, encontros ao ar livre e manifestações de vida urbana e comunitária, que beneficiam o desenvolvimento humano e o relacionamento entre as pessoas (OLIVEIRA e MASCARÓ, 2007).

Jacobs (2007), relata também sobre os parques de bairro, comumente considerados uma dádiva conferida à população carente das cidades, pois as pessoas dão utilidades aos parques e fazem deles um sucesso, ou então não os usam e os condenam ao fracasso.

Em Indiana, cidade pequena e afastada dos grandes centros urbanos, as crianças costumam se reunir na praça da igreja para brincar e trocar experiências, isso tudo sob o olhar dos adultos, que costumam se sentar na calçada em suas cadeiras de área com o intuito de se sociabilizarem. 


\section{Vitalidade dos bairros da cidade}

A vitalidade de uma urbe pode ser compreendida como uma grandeza dinâmica de movimento e energia. Os atores da produção destas "energias" urbanas são consequentemente elementos vitais para a afirmação e qualificação urbanas (Guerra et al, 2006).

Para que um bairro seja considerado "vivo", é necessário que seja frequentado e utilizado pela população em diferentes horários, por pessoas com interesses diferentes (morar, circular, trabalhar, etc), para que tal vitalidade seja alcançada. Jacobs (2007) ressalta que eles devem ter mais de uma função principal, ou seja, ter combinação de usos como: moradias (diurno/noturno), empresas (diurno), comércio (diurno), prestação de serviços (diurno), centros culturais e lazer (noturno). É importante saber que sobre a mescla de combinação de usos principais, o mais importante é o resultado cotidiano da mistura de pessoas como grupo de sustentação econômica.

No centro da cidade de Indiana - SP é percebida a mistura adequada de usos principais como residência, comércio, prestação de serviço e o lazer da praça central. O centro representa o local de trocas social, cultural e econômica desta cidade, visto que se trata de uma cidade de pequeno porte e do interior do estado, ainda consegue manter essas características positivas, diferentes de cidades de portes maiores, onde o centro urbano torna-se demasiadamente especializado em comércios, ficando ociosa a infraestrutura implantada, e por vezes perigoso durante alguns períodos do dia (VILLAÇA, 1998).

A cidade de Indiana, não possui uma grande diversidade de usos, nem oferece muitas opções para entretenimento, fazendo-se necessário aos moradores a busca em cidades vizinhas, principalmente aos finais de semana. O único lugar que possibilita o uso coletivo, para entreter, realizar eventos, reunir amigos ao final de tarde, é a praça da cidade. Que estabelece uma função principal no papel troca de relações entre as pessoas. Por Indiana ser uma cidade de pequeno porte pode se estabelecer tal como uma unidade como um todo, sendo acentuada a forma com a qual as pessoas cuidam umas das outras.

\section{Segurança das ruas}

Segundo Jacobs (2007), não podemos deixar as ruas cegas, deve-se ter usuários transitando ininterruptamente, para aumentar na rua o número de olhos atentos observando as calçadas. Uma rua movimentada consegue garantir a segurança. Deve sempre existir olhos para a rua, os olhos daqueles que podemos chamar de "proprietários" naturais da rua. Podemos classificar Indiana como uma cidade segura, pois além do policiamento, o monitoramento das ruas e calçadas se dá pela própria comunidade. Portanto o requisito básico da vigilância é sempre haver 
estabelecimentos e espaços públicos que sejam utilizados em diferente horários e também à noite: lojas, bares e restaurantes, são exemplos, pois atuam de forma bem variada e complexa para aumentar a segurança nas calçadas.

A boa iluminação das ruas é importante, proporciona um conforto às pessoas que precisam andar nas calcadas. No entanto, as luzes não têm efeito algum se a houver olhos para ela, segundo Jacobs (2007).

Outra característica que constatamos foi à diversificação de edifícios antigos, que são um dos pontos chaves apresentado por Jacobs (2007), onde a cidade deve ter uma combinação de edifícios com idades e estados de conservação diferentes. A grande parte do comércio local, concentrado ao redor da praça, ocupam edificações antigas, dentre as quais são mercearias, padarias, bares.

Nota-se na cidade analisada a presença de quadras curtas e a inexistência de avenidas extensas, aumentando consideravelmente o número de trajetos diferentes que uma pessoa pode fazer para alcançar o mesmo destino. Desta forma, a vizinhança fica mais assistida.

\section{CONSIDERAÇÕES FINAIS}

As observações e análises realizadas na cidade de Indiana - SP tornam possível a conclusão de que os espaços públicos urbanos são de fato utilizados pela população. Um dos fatores que influenciam essa realidade é o fato da cidade estudada ser uma cidade de pequeno porte e do interior do estado, com isso mantém uma rotina mais pacata, típica de cidades como a mesma. Essa realidade pode ser considerada um ponto positivo e auxilia na qualidade de vida da população.

O caminho para o planejamento para a cidade baseia-se na consciência da cidade real, que pode ser conhecida através levantamentos da rotina da população e também de indicadores sociais. Para isso a discussão apresentada se torna uma ferramenta que colabora para a descoberta das reais necessidades da cidade e de sua população.

O exercício da cidadania frente aos problemas que envolvem o crescimento da cidade com participação efetiva e busca de novas propostas através do debate social é a mais importante contribuição, para que o pensamento crítico possa ser disseminado. Este pensamento estudado serviu de suporte teórico para "pensar" a cidade e nos aproximar da realidade local através da análise da cidade de Indiana. 


\section{REFERÊNCIAS}

ALBANO, Mayara Pissutti. A Importância do Planejamento Urbano Ambiental - A Habitação Social e a Expansão Urbana em Presidente Prudente - SP. 2013. Dissertação (Mestrado) Universidade do Oeste Paulista,Presidente Prudente.

BALULA, Luís. Espaço Público e a Criatividade Urbana. A dinâmica dos logares em três bairros culturais. Cidades - Comunidades e Territórios. Dez 2010. N²0/21, pp 43-58.

BORJA, Jordi, e MUXI, Zaida. El Espacio Público, Ciudad e Cidadania, Electa, 2003.

GUERRA, I., MOURA, D., SEIXAS, J. e FREITAS, M. J. A Revitalização Urbana - Contributos para a definição de um conceito operativo. In Cidades, Comunidades e Territórios, №12-13, Centro de Estudos Territoriais, ISCTE (2006).

INDIANA - SP. Website oficial do município. Disponível em: http://www.indiana.sp.gov.br. Acesso em: 13 de Abril de 2014.

JACOBS, Jane. Morte e vida de grandes cidades. Martins Fontes, 2000.

OLIVEIRA Lucimara Albieri de; MASCARÓ Juan José. Análise da qualidade de vida urbana sob a ótica dos espaços públicos de lazer. Ambiente Construído, Porto Alegre, v. 7, n. 2, p. 59-69, 2007.

VILLAÇA, F. Espaço Intra-urbano no Brasil. São Paulo: Studio Nobel: FAPESP: Lincoln Institute, 2001. 373p. 